\title{
Fricciones ontológicas en las colaboraciones entre huicholes y ambientalistas
}

\section{Ontological Frictions in the Collaboration between Huichols and Environmentalists}

\author{
Johannes Neurath \\ SUBDIRECCIÓN DE ETNOGRAFÍA, MUSEO NACIONAL DE ANTROPOLOGÍA-INSTITUTO \\ NACIONAL DE ANTROPOLOGÍA E HISTORIA, johannes.neurath@gmail.com
}

Durante las últimas décadas, wixaritari (huicholes) del Occidente de México han sido protagonistas de importantes conflictos ecológicos. Aquí nos enfocaremos en las fricciones entre ellos y los activistas no indígenas con quienes colaboran. En términos de la antropología de las ontologías de Descola, podríamos hablar de la coexistencia del naturalismo científico, animismo huichol y analogismo New Age. No hay que confiar demasiado en este tipo de categorizaciones. El punto más interesante es que los animistas entienden mejor a las otras ontologías, y pensamos que los ambientalistas y activistas se beneficiarían de una mejor comprensión de la cosmopolítica huichola. Para los wixaritari, la práctica política siempre parte de la defensa de la autonomía y de los derechos indígenas. Por otra parte, vale la pena insistir que para los huicholes la naturaleza no es algo dado, sino que se produce durante rituales de iniciación, así que los wixaritari no solamente defienden una geografía ritual ya existente, sino también el derecho de reinventarla. Conviviendo con los wixaritari es fácil darse cuenta que su meta no es perseguir una meta ambientalista, como salvar el planeta, sino de fortalecer su organización comunitaria y, de cierta manera, lo que hacen con esta práctica es crear, recrear, y si queremos decirlo así, salvar el mundo.

PaLABRAS ClaVE: huicholes, ecología, paisaje ritual, ontologías, autonomía.

In recent decades, Wixaritari (Huichols) of western Mexico have been protagonists in highprofile ecological conflicts. This paper focuses on the frictions between them and the nonindigenous activists and environmentalists with whom they collaborate. In terms of Descola's anthropology of ontologies, we could speak of the co-existence of Wixarika animism, New Age analogism and scientific naturalism, but should not rely too much on categorizations of this type. The salient point here is that Wixarika animists understand the other ontologies better than vice versa, so we conclude that ecologists and activists would benefit from enhancing their understanding of how Huichol cosmopolitics work. For Wixaritari, political practice always begins with the defense of autonomy and indigenous rights, but it is also important to emphasize that for them nature is not something given; rather it is produced through initiation rituals, so Huichols defend not only a pre-existing ritual geography, but also the right to permanently reinvent it. Living with Huichols makes it 
easy to understand that their aim is not to pursue some broad environmental goal like "saving the planet", but to strengthen their community organization; so in a certain sense what they do through such practices is create, re-create and, we might say, save the world.

KEYworDs: huichols, ecology, ritual landscape, ontologies, autonomy.

Fecha de recepción: 19 de junio de 2017 / Fecha de aceptación: 31 de marzo de 2018 / Fecha de versión definitiva: 24 de abril de 2018

\section{INTRODUCCIÓN}

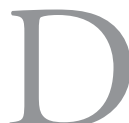

urante las últimas décadas los huicholes o wixaritari han sido protagonistas de varias campañas ecologistas exitosas. El conflicto con más eco mediático ha sido, sin duda, la controversia sobre la minería en los alrededores de Real de Catorce, San Luis Potosí, que afectaría al conjunto de lugares de culto huicholes ubicado en el semidesierto que ellos llaman Wirikuta. Las protestas contra estos proyectos culminaron en la primavera del 2012. En 2008 había otra movilización importante, cuando la comunidad de Tuapurie bloqueaba la construcción de una carretera asfaltada de Bolaños a Huejuquilla El Alto, en el Norte de Jalisco, que fue un proyecto promovido por el gobierno del estado. A finales de los ańos 1990, comunidades huicholas y las Organizaciones No Gubernamentales (ONG) lograron parar otro proyecto de carretera, que hubiera afectado una serie de lugares de culto en Wirikuta. En todas estas luchas y alianzas entre comunidades huicholas, organizaciones y activistas de la sociedad civil han logrado sus objetivos, y no es poca cosa que se hayan logrado frenar los proyectos de una empresa transnacional tan poderosa como First Majestic Silver.

¿Por qué, entonces, hablar de "fricciones"? Observamos que mientras los huicholes recurren al apoyo de ecologistas para lograr que se respeten sus derechos y no se destruyan sus sitios sagrados; los ecologistas recurren a los huicholes, que son mundialmente famosos por su chamanismo de peyote y su arte, para que sus luchas por la defensa del ambiente lleguen a los medios masivos. Normalmente lo que se necesita es que la prensa internacional empiece a publicar algunas notas sobre el tema en cuestión, para que el gobierno de México entre en acción y se cumplan las normas vigentes. En teoría, los marcos jurídicos son bastante favorables para el ambiente y los gru- 
pos indígenas; lo que muchas veces falla es la aplicación de los mismos. Hasta ahora, muchas de las luchas que involucran wixaritari han tenido un desenlace positivo, pero pienso que vale la pena detenerse un momento para analizar algunos de los malos entendidos que se presentan en estas colaboraciones mediatizadas para generar la presión política necesaria para lograr que las normas se cumplan.

Es importante aclarar que mi trabajo etnográfico con ecologistas no tiene la misma calidad de mis investigaciones entre los wixaritari, sobre todo, no tiene la misma sistematicidad. Cuando trabajaba en mi tesis de doctorado aún me inclinaba a una definición más tradicional de la etnografía y me limitaba a las comunidades y "prácticas tradicionales" de los huicholes. Si ahora comenzara un proyecto de trabajo de campo estudiaría los wixaritari dentro de sus complejas redes de interacción, que incluyen un gran número de fenómenos, entre ellos el activismo ecologista, los mercados de arte, los medios de comunicación, el denominado neochamanismo y el New Age. Sin embargo, aunque no me he enfocado específicamente en estos temas, cuento con observaciones sobre las relaciones entre los huicholes y los huicholeros que me parecen relevantes. Podría decir que este estudio no deriva de un proyecto de investigación específico, sino de la práctica. A fin de cuentas he estado involucrado como experto y mediador en muchas de las luchas mencionadas. El término "huicholero" se usa para los amigos y fanes de los huicholes, tanto de su arte como de su chamanismo. Ahora bien, cuando hablo del discurso de los huicholeros, me refiero tanto a experiencias directas como a lo que se ve reflejado en innumerables publicaciones escritas, videos, blogs y otros medios. Desde luego, no pretendo abarcar toda la temática, y tampoco quisiera simplificar. Hay gran diversidad de ideas y tendencias entre los ecologistas, pero quiero hacer una crítica constructiva en relación con situaciones, ideas y actitudes que se observan a menudo.

Como antropólogo no puedo evitar expresar mi preocupación por los discursos esencialistas de parte de ecologistas y huicholeros. Nadie dudaría que tecnócratas "neoliberales" e indígenas no estén en la misma frecuencia, pero mucha gente no se da cuenta que los wixaritari y sus aliados no indígenas también están separados por 
abismos conceptuales, culturales o existenciales. Para empezar, las premisas de huicholes y ecologistas no son las mismas. Los primeros se preocupan, primero que nada, por sus derechos de autonomía -mantener una organización política, ritual y territorial propia-; por el derecho a ser consultados en todos los asuntos que les conciernen -recientemente garantizado con unas reformas constitucionales-; por su libertad de culto -el derecho de usar peyote, de cazar venado, la protección de los lugares sagrados en el paisaje-; y, de manera general, por el derecho de ser "diferentes" y no asimilarse al resto de la población mexicana. Los ecologistas quieren salvar el planeta y, de la lista interminable de problemas que se presentan, eligen casos paradigmáticos donde existe una cierta posibilidad de ganar. Me queda claro que durante los momentos más álgidos de las luchas políticas nadie se puede tomar el tiempo para reflexionar sobre asuntos tan teóricos, pero ahora estamos en una fase de relativa calma y creemos que este ejercicio puede ser de utilidad, sobre todo porque podría permitir que los activistas tomen más en serio las prácticas y concepciones de sus aliados indígenas.

Hablando de malos entendidos, es importante aclarar que, de cierta manera, los huicholes suelen saber más sobre nosotros, que nosotros sobre ellos. Para ellos conocer lo teiwari (mestizo, vecino) es estratégico, sobre todo porque les importa saber ser mestizo o funcionar como uno. La alternativa no es ser indio (tewi) o mestizo (teiwari), sino ser indio o indio y mestizo -poder ser y funcionar como sea más conveniente en cada circunstancia-. Destacaría, entonces, un cierto desequilibrio antropológico. Tanto los no indígenas urbanos, como los mestizos locales de la región del Gran Nayar, suelen tener ideas distorsionadas y exageradas sobre los wixaritari, considerándolos colectivamente como artistas, sabios, curanderos, chamanes o brujos que se transforman en lobos. Pero no se puede decir que los huicholes no tengan una idea bastante clara sobre los teiwarixi. En términos de una reverse anthropology, los huicholes tienen la ventaja de entender bastante bien a su otro.

Tal vez por falta de una mayor presión exterior, vimos como, recientemente, surgieron conflictos entre comunidades wixaritari e importantes ONG, donde las primeras acusaron a las segundas de 
ser impositivas y de no respetar los procesos políticos internos de los huicholes. El Consejo Regional Wixarika rompió relaciones con las ONG que lideraban la defensa de Wirikuta, y varias comunidades les retiraron el permiso de representarlos legalmente (véase http:// consejoregionalwixarika.org/?p=269). No tengo dudas que en el momento que se avecine una nueva crisis política se retomará la colaboración entre los ecologistas, tal vez de otras organizaciones, y los huicholes ¿Pero no sería bueno que los activistas tuvieran más sensibilidad o, incluso, conocimiento antropológico?

Es notable que aún los huicholeros más experimentados tienen dificultades para entender los liderazgos y la organización comunitaria wixarika. He observado, en muchas ocasiones, su actuar poco afortunado en las asambleas y reuniones. Por otra parte, algunas características de lo que sería la ecología desde el punto de vista wixarika podrían obligar a los ambientalistas a replantear sus prioridades y darle más importancia al tema que más interesa a los wixaritari: la defensa de los derechos indígenas. Veremos que de esto, incluso, podría derivar una nueva concepción de la ecología.

En este momento, el activismo ecologista no destaca, precisamente, por una gran sensibilidad por temas de diversidad. Se usan, sin pensar mucho, toda clase de concepciones estereotipadas sobre los pueblos indígenas, para argumentaciones esencialistas que apelan a la mala conciencia de las clases medias urbanas. El problema es que estos clichés no son inocentes, sino paternalistas y colonialistas (Rosaldo 1991, Trouillot 1991, Sahlins 1999). Por otra parte, mientras que esto no cambie, los mismos ecologistas se privan de la posibilidad de aprender de los pueblos indígenas. Por ejemplo, podrían aprender que hay muchas maneras de relacionarse con la "naturaleza”, más allá de la explotación utilitarista y la idealización romántica, que desde un punto de vista, no serían más que dos aspectos de un mismo discurso (Latour 1999, 2013; Descola 2013).

Anna L. Tsing describe una situación comparable donde pueblos aborígenes de Borneo, ambientalistas internacionales y amigos indonesios de la naturaleza colaboran a pesar de las "fricciones" que se dan debido a incompatibilidades culturales (Tsing 2004). Sin embargo, en los contextos que ella analiza, los nativos dayak de la montańa 
Meratus únicamente operan a un nivel local, mientras que tanto los ecologistas que protegen como las corporaciones que destruyen el ambiente se caracterizan como internacionales. Ahora bien, en el caso de los huicholes tratamos con un grupo étnico muy diferente, que no es menos globalizado que sus aliados o adversarios no indígenas. En las luchas que hemos mencionado, no solamente son los ambientalistas quienes apoyan a los pueblos originarios, también los huicholes hacen un favor a los ecologistas. Sin embrago, aunque la agenda política de los huicholes está bien definida -defender la autonomía de sus comunidades-, en las luchas ecologistas se ven obligados a acoplar su discurso con las necesidades de sus aliados, quienes se autorrepresentan como protectores de la "diversidad cultural y biológica", de los animales, plantas y minorías étnicas amenazados por el avance avasallador del mundo industrializado. Pero vale la pena recordar que los huicholes se oponen a proyectos de empresas de diferentes instancias del gobierno no (en primer lugar) porque temen por el medio ambiente, sino porque insisten en su derecho a ser consultados. La carretera Huejuquilla-Bolaños hubiera servido a muchos wixaritari-esto nunca se cuestionó-, pero no podían permitir una obra de construcción en su territorio comunal iniciada sin su permiso. En este caso, las que se solidarizaron con los huicholes en esta lucha eran organizaciones indígenas preocupadas por defender la autonomía, como el Congreso Nacional Indígena, pero también grupos ecologistas preocupados por los bosques de pino de la sierra. Notablemente, en la campaña mediática, el discurso ambientalista resultó mucho más eficiente. Al final se logró un triunfo importante sobre un proyecto tecnócrata, pero el discurso ecologista eclipsó la lucha por los derechos indígenas.

\section{El asesinato De UNA PIEdRa y el Avatar meXicano}

Siguiendo las propuestas de la antropología del denominado "giro ontológico" (Wagner 1977, 1981; Viveiros de Castro 1998, 2002, 2015; Descola 2005; Descola ed. 2010; Breton et al. 2006; Henare, Holbraad y Wastell 2007; Carrithers et al. 2008), nos proponemos profundizar sobre las diferencias entre lo que se ha llamado el animismo o multinaturalismo de pueblos amerindios, como los wixarika, y 
las mentalidades o cosmovisiones dominantes entre los activistas que, normalmente, provienen de las tradiciones occidentales.

La lucha del año 2008 fue una experiencia clave que me ayudó entender la importancia de poner más atención a las diferencias ontológicas que pueden estar en juego, no solamente en la relación entre gobiernos tecnócratas, empresas depredadoras y poblaciones aborígenes, como en las situaciones que analiza Elizabeth Povinelli en Australia (2013), sino también en la colaboración entre pueblos indígenas y organizaciones que supuestamente los apoyan y defienden. Al iniciar las obras, sin haber consultado o solicitado el permiso de la comunidad, los obreros destruyeron un lugar sagrado huichol de nombre Hutsekie, Casa del Oso. La piedra que, según los huicholes, es el Oso, fue enterrada bajo toneladas de material. Liffman, Neurath, Lira, Carrillo y Ruy-Sánchez (2008) redactamos, entonces, un informe, pero el INAH Jalisco se declaró incompetente. El objeto en cuestión era una simple piedra natural, no una escultura o un artefacto que podría ser considerado patrimonio. Para los huicholes, se trataba de un crimen equivalente a un asesinato. Nos dimos cuenta que, incluso para una institución como el INAH, los conceptos indígenas de naturaleza, cultura y patrimonio simplemente no son relevantes.

De una manera no tan diferente, cuando se trataba de defender el desierto de Wirikuta de las mineras, lo que a muchos ecologistas preocupaba más no era la destrucción de sitios sagrados, sino la contaminación del agua o la desaparición de ciertas especies. La presencia de prácticas indígenas "milenarias" era bienvenida, porque daba visibilidad mediática a la lucha, pero no era lo principal. La situación recordaba a lo que Kockelman describe en su estudio sobre una ONG alemana que defiende el bosque de niebla en Alta Verapaz, Guatemala: "El valor último de los ecologistas es la conservación de la biodiversidad; en otras palabras estas intervenciones no eran humanitarias en el sentido estricto de la palabra. Las poblaciones indígenas jugaron un rol importante para lograr un fin a favor de la biodiversidad, pero no era un fin en sí mismo" (Kockelman 2016). ${ }^{1}$

1 "The ultimate value of the ecologists is biodiversity conservation; in other words, these interventions were not humanitarian in the strict sense. That is, while the indige- 
Desde la perspectiva de la ecología, o de la protección del patrimonio, uno de los retos más difíciles es entender lo que serían los conceptos wixarika de naturaleza o patrimonio. Y diría que esto no es una simple sutileza teórica, sino algo con muchas implicaciones para estas prácticas políticas. Los ecologistas que he observado en las diferentes luchas que involucran a los huicholes lamentablemente reproducen muchas veces un discurso basado en ideas de la antropología culturalista de entre finales del siglo xIx y mediados del siglo xx. En este discurso, los huicholes son una "tribu primitiva": un grupo que vive aisladamente en una inaccesible serranía donde aún perdura la época prehispánica, prehistórica o, incluso, neolítica.

Como sabemos, esta idea la encontramos claramente expresada en El México desconocido de Carl S. Lumholtz, la clásica obra sobre Five Year's Exploration Among the Tribes of the Western Sierra Madre... (Lumholtz 1902). Ahí leemos la célebre frase que dice que los huicholes "siguen disfrutando prácticamente del mismo estado de barbarismo que en los tiempos cuando Cortés pisó primero las tierras americanas" (Lumholtz 1902, 2, 23). No tiene caso criticar las ideas de un viajero decimonónico como Lumholtz desde la perspectiva de hoy. Evidentemente, un explorador de su época no se exponía a los peligros de selvas, barrancas y desiertos para constatar que todos los pueblos aborígenes encontrados son el resultado de complejos procesos históricos, como decimos hoy. Lo que Scribner's Magazine y los demás patrocinadores de sus expediciones esperaban de Lumholtz eran "descubrimientos": tribus perdidas, tumbas misteriosas, artefactos exóticos y especies nuevas.

Más problemático es que la visión de Lumholtz se haya convertido en una concepción estereotipada, reproducida acríticamente por mucha gente, entre ella, los activistas ecologistas de hoy, sin dejar de mencionar a los amantes del arte y de la artesanía indígenas, o los periodistas que escriben en revistas populares como National Geographic. Más que "descubridor", Lumholtz puede considerarse el "inventor" de los huicholes, el fundador del discurso primitivista

nous populations played a necessary role as a means to the end of biodiversity, they were not an end in themselves". 
sobre este grupo. El escritor y periodista Fernando Benítez, por ejemplo, al iniciar un reportaje de viaje a la sierra huichola, afirma que "de Tepic, es decir, del siglo XIX -no podemos afirmar que viva en el siglo XX-, pasamos sin transición al neolítico" (Benítez 1984, 63). El mismo autor también afirma que "no habiéndose modificado la economía del neolítico, tampoco se han alterado las estructuras sociales y religiosas de los grupos indios atomizados en las montañas o aislados en los bosques" (Benítez 1984, 601). Para el antropólogo norteamericano Peter T. Furst, los huicholes eran la "única población de Mesoamérica cuyo universo ideológico aborigen ha permanecido básicamente inalterado por la influencia cristiana” (Furst 1972, 7). Furst y Barbara Myerhoff afirmaron que

los ocho a diez mil supervivientes habitan las regiones más aisladas y agrestes de la Sierra Madre Occidental [...] y ocupan una posición única entre los indígenas mexicanos [...] Al parecer sus creencias y rituales han permanecido virtualmente estáticos durante los cuatro siglos posteriores a la Conquista y el sincretismo que tipifica a otros indios en Mesoamérica está casi totalmente ausente entre los huicholes (Furst y Myerhoff 1972, 55).

Myerhoff incluso llegó a plantear que los huicholes evidencian un pasado reciente como cazadores y han realizado una "transición incompleta a la agricultura" (Myerhoff 1974, 59).

Junto con esta insistencia en una ininterrumpida continuidad histórica, el enfoque simbolista es un aspecto central de la antropología culturalista. Los huicholes adoran a la naturaleza, en especial, el peyote, el venado y el maíz, y su meta es mantener el equilibrio cósmico (Furst 1968, 1973, 1987; Myerhoff 1970; Schaefer y Furst 1996; Powell y Grady 2010). Pero todas estas "creencias milenarias" solamente se mantienen mientras que los huicholes no estén arrastrados por la modernización y las nocivas influencias foráneas.

Para la antropología académica este discurso ya es prácticamente una curiosidad historiográfica, pero, en el ecologismo de inspiración New Age, la antropología simbólica norteamericana de Furst y Myerhoff sigue vigente. Como en la antropología de los años sesen- 
ta, los huicholes se describen como los "últimos practicantes" de una espiritualidad arcaica que busca mantener el universo en balance.

Cuando el director del documental Huicholes: The Last Peyote Guardians me entrevistó para su proyecto, le sugerí -incluso le insistí-cambiar el título de este documental, pero no logré convencerlo. Actualmente la película se anuncia así:

Una historia urgente acerca del Pueblo Wixárika, una de las últimas culturas prehispánicas vivas en Latinoamérica, y su lucha ante el gobierno mexicano y corporaciones transnacionales mineras para preservar Wirikuta, su territorio más sagrado, donde crece el peyote, la medicina ancestral que mantiene vivo el conocimiento de este pueblo emblemático de México. ${ }^{2}$

La película fue muy exitosa y sin duda sirvió para defender los lugares sagrados de Wirikuta. ¿¿Hubiera tenido el mismo impacto con un título menos esencialista? ¿Es realmente necesario insistir en que los huicholes sean "prehispánicos" para que su cultura se considere valiosa? ¿Acaso los grupos étnicos que no son tan antiguos, ni tan tradicionales no tienen los mismos derechos?

El problema es que este discurso culturalista mencionado lo encontramos constantemente en lo publicado por activistas y organizaciones no gubernamentales. Claro, a veces no estoy seguro si la tendencia de los huicholeros de primitivizar y exotizar a los huicholes es parte de una estrategia mediática, o si realmente se lo creen. Al convivir con los huicholes deberían darse cuenta que las cosas no son tan así, pero los mitos son muchas veces más fuertes que la experiencia propia.

En este trabajo no puedo ofrecer un panorama completo, ni una historia detallada del activismo en la región huichola. Como dijimos, tampoco queremos negar que hay una diversidad en los proyectos y enfoques. Hay grupos especializados como Wixarika Research Center ${ }^{3}$ y grandes organismos internacionales como Cul-

${ }^{2}$ https://huicholesfilm.com/es/sinopsis/

${ }^{3}$ Fundado por Juan Negrín Fetter y con sede en Oakland, California, este grupo se ha dedicado a la defensa de los bosques de la zona wixarika y a la promoción de artistas indígenas. 
tural Survival. ${ }^{4}$ Entre las ONG nacionales destacan actualmente CHAC $^{5}$ y AJAGI. ${ }^{6}$ La primera se ha especializado en la defensa legal de las comunidades y de sus territorios, la segunda es un grupo ambientalista que desde 1995 promueve la protección del semidesierto de Wirikuta. Conozco la mayoría de las organizaciones y he colaborado con algunas en varias ocasiones, así que me atrevo a hacer afirmaciones sobre como piensa la mayoría de los activistas.

Tratando de hacer etnografía de los huicholeros, podríamos decir que los activistas comparten un conjunto de ideas que podríamos llamar su "visión del mundo": una "tribu" indígena (como los wixaritari) se confronta a los mismos peligros que una especie endémica (como el peyote). Ambas, por definición, están en peligro de extinción. Cuando su medio ambiente sufre un daño o la destrucción, el grupo étnico que lo habita está condenado a desparecer. Ocasionalmente usan una metáfora que parece inocente, pero es sintomática por negar la agentividad de los huicholes: se afirma que Wirikuta es el Avatar mexicano, refiriéndose a la película de ciencia ficción de James Cameron del año 2009 (véase Lamberti 2014). Lydia Cacho, una conocida periodista, expresó esta idea en su columna "Plan B" que se reproduce en los periódicos El Universal y El Informador: "Quienes vimos la película Avatar vimos la indignación de la destrucción de[l] árbol sagrado de los návi y el inhumano ataque destructivo para explotar minas ignorando una cultura milenaria. Este bien podría ser el Avatar mexicano y no debemos admitirlo" (http://www.informador.com.mx/mexico/2011/277573/6/ el-avatar-mexicano.htm). Pero esta comparación apareció primero en un blog ecologista. Pablo Alarcón-Cháires publicó un comentario en la página del Wixarika Research Center (Oakland):

la situación actual en México es acorde a las circunstancias planteadas en la película [Avatar]: los na'vi son el pueblo indígena wixarika o huichol;

${ }^{4}$ Organización que defiende grupos étnicos de todo el mundo. Fundada por el antropólogo David Maybury-Lewis tiene su sede en Cambridge, Massachusetts.

${ }^{5}$ Conversación Humana A.C., fundado por Humberto Fernández Borja.

${ }^{6}$ Asociación Jalisciense de Apoyo a Grupos Indígenas A.C. Su dirigente es el abogado Carlos Chávez. 
los soldados emisarios de los intereses económicos están encarnados por la policía del Estado de San Luis Potosí; el planeta Pandora, es el actual territorio sagrado huichol del desierto de Wirikuta, cercano a Real de Catorce; y el Árbol de las Almas de Pandora, es la planta sagrada jicuri o peyote (http://wixarika.mediapark.net/sp/sp_comentarioPabloAlarconChairesWirikuta.html).

Tal como los návi dependen de su árbol sagrado, los huicholes dependen del peyote. Los návi se comunican con su árbol y de éste obtienen ciertos "superpoderes" y, aparentemente, se cree que el peyote brinda a los huicholes su famosa espiritualidad chamánica. De esta manera, se reproducen las ideas de que los huicholes requieren la existencia de un medio ambiente intacto para seguir existiendo, y que el ritual huichol, por esta misma razón, está enfocado al mantenimiento del equilibrio cósmico. La figura del White Saviour es, desde luego, también sumamente problemática y no se reproduce solamente en películas de Hollywood, sino también en el quehacer cotidiano de muchas ONG.

Muchas otras ideas equivocadas sobre los huicholes se acoplan a este modelo. Cultural Survival insiste que los huicholes han tenido una economía de subsistencia que -lamentablemente- se está perdiendo. "The Huichol can no longer entirely rely on their impoverished lands for subsistence". ${ }^{7}$ Wixarika Research Center retoma viejas especulaciones de antropólogos que plantean que Wirikuta es el verdadero lugar de origen de los huicholes. Por eso retornan ahí en sus rituales. ${ }^{8}$

Ahora bien, no sobra insistir en que la antropología y la historia contemporáneas piensan bastante diferente. Hay evidencia bastante sólida que los huicholes no han migrado desde Wirikuta a sus territorios actuales, ni que hayan sido cazadores-recolectores. Más bien, llevan cultivando maíz desde hace muchos siglos. El viaje al semidesierto no es parte del "eterno retorno del mito", sino que surgió a partir de actividades comerciales que coras y huicholes practican des-

${ }^{7}$ https://www.culturalsurvival.org/publications/cultural-survival-quarterly/art-ecology-and-huichols-future

${ }^{8}$ http://www.silene.es/documentos/Wirikuta.pdf 
de hace siglos (Weigand 1992, 184-185). Lo más importante es que los wixaritari nunca fueron un grupo aislado replegado en una sierra inaccesible, sino desde que existen fuentes históricas han sabido relacionarse con otras poblaciones. Ver a los huicholes como víctimas de los procesos de conquista y globalización impide entender su dinámica cultural, más bien son la prueba de que un grupo relativamente pequeño puede ser protagonista de la historia (Neurath 2002).

A nivel teórico, un punto especialmente relevante sería que las prácticas de grupos como los indígenas ya no se entienden como un actuar simbólico sobre el entorno. En la ontología multinaturalista, que caracteriza a muchos pueblos amerindios, la naturaleza en un principio no está dada, sino que es producto de la actividad humana. En este sentido, hemos señalado que el mundo wixarika existe gracias al esfuerzo de los wixaritari (Neurath 2015a, 2018). La naturaleza es cultura.

El carácter artificial de la naturaleza se aprecia especialmente bien en los rituales relacionados con Wirikuta. Tanto el peyote como la plata son resultado de transformaciones experimentadas por humanos, la transformación de los ancestros wixaritari en peyote es resultado de un rito de iniciación perfecto, la transformación de los ancestros no indígenas en plata es algo equivalente, pero de valor menor. Cuando los wixarika están en Wirikuta no "ingieren" el peyote como si éste fuera una droga, fármaco o "enteógeno" (en el sentido de Wasson, Hoffman y Ruck 1980, véase Znamenski 2007), sino que practican rituales cosmogónicos e iniciáticos donde se toma la perspectiva de la planta alucinógena. Se identifican con un venado presa de cacería y el animal se transforma en peyote. Como resultado, los peyoteros inventan una entidad cosmopolítica diferente al mundo no indígena. Wirikuta y toda la parte superior y luminosa del cosmos son, entonces, no tanto parte del ambiente natural, sino resultados de la experiencia wixarika.

Como hemos descrito detalladamente en otros textos (véase Neurath 2002), los centros ceremoniales wixaritari organizan anualmente (o, por lo menos, cada dos años) un grupo ritual de "portadores de jícaras" (xukuriłkate, jicareros), donde los integrantes intentan convertirse en "personas-peyote" (bikuritamete, peyoteros), 
en "los que saben soñar" (mara'akate, personas iniciadas) y en sus propios antepasados, es decir, en los miembros originales de la comunidad, los primeros seres humanos. Tomar la perspectiva del peyote y convertirse en él es la experiencia que da origen a la luz y al conocimiento. La búsqueda de visiones es una experiencia sacrificial. Los peyoteros se identifican con una presa que se entrega voluntariamente a los cazadores y muere. $\mathrm{Al}$ mismo tiempo, se abstienen de todo lo que tiene que ver con la oscuridad, con el mar en el Poniente, y con el sueńo: casi no duermen, no ingieren sal, aguantan las largas caminatas y no cometen transgresiones sexuales. Después de todas estas purificaciones, lo que el iniciado logra es ver el mundo desde la perspectiva del cactus alucinógeno: el mundo visto con los ojos de una persona-peyote es muy luminoso y, por esto, existe la luz.

Como ha señalado Paul Liffman (2012), el sacrificio no tan perfecto (o mal llevado a cabo) que practican los que no logran la iniciación solamente da origen a la plata. La plata es un peyote "plan B" para los mestizos, que son excluidos de la iniciación, y aquellos wixaritari que no la logran. El mundo visto desde la perspectiva de los no iniciados o no indígenas se constituye de otra manera. Se puede decir que es el mundo de lo que se puede comprar con dinero.

Vale la pena mencionar que en los mitos huicholes se habla sólo de la plata. Otros minerales que se explotan en la región aparentemente no se consideran tan importantes. Desde luego, la existencia simultánea de peyote y plata en un lugar expresa la jerarquía entre mara'akate y no iniciados, que se equipara con la que existe, según los wixaritari, entre huicholes y mestizos. La jerarquización entre iniciados y no iniciados, huicholes y mestizos es un principio que estructura todo el cosmos wixarika. La convivencia entre estos dos ámbitos no puede ser muy armónica. Lo que se supone es lo siguiente:

—Los de "abajo", en especial los mestizos, son ignorantes, flojos, poco cultos, perdidos, "mareados", irresponsables y egoístas.

-Los de "arriba" son austeros, "caminan, sin perderse, sobre las huellas de los ancestros (yeiyari)", practican el sacrificio y, por ende, logran obtener poderes especiales de transformación y creación.

La cosmología wixarika es dualista, pero asimétrica, así que no es productivo interpretarla a partir de nociones de equilibrio. Remito a 
trabajos previos donde explico con detalle porque no considero que "balance cósmico" sea un término adecuado para acercarse a la cosmología wixarika (Neurath 2002, 2015a, 2015b, 2018). En la geografía wixarika, hay un contraste geográfico muy claro entre "arriba" y "abajo", entre el semidesierto en el Oriente y la fértil planicie costera en el Poniente. El territorio de las comunidades wixaritari se ubica en medio, en la Sierra Madre Occidental. Como en otras cosmovisiones mesoamericanas, hay un isomorfismo cuerpo-cosmos (López Austin 1980, Galinier 2004, Monaghan 1995, 98). Wirikuta corresponde a la cabeza (y es la cabeza del mundo); la costa, a los órganos sexuales; y el ombligo del mundo se ubica en una barranca de la sierra. Asimismo, Wirikuta corresponde al día y a la temporada de las secas y la costa a la noche y a las lluvias. El otońo es "cuando amanece". Las serpientes de lluvia son el alma vital o la respiración (iyari) del mundo. El cuerpo es un microcosmos, el mundo es un macrocuerpo.

Todo este sistema muy elaborado de analogías muestra asimetrías importantes, tanto morales, como en lo que se refiere a la experiencia ritual y del tiempo. Únicamente el ámbito de la noche siempre ha existido y siempre existirá. La luz del amanecer, en cambio, debe encontrarse o, más bien, inventarse en una experiencia visionaria.

Esta misma asimetría también se aprecia muy bien en el caso de la arquitectura de los templos que conforman los centros ceremoniales huicholes (Neurath 2015a). Los edificios tipo tuki y xiriki deben renovarse cada cinco años, pero solamente se vuelven a hacer los techos de zacate, los muros permanecen iguales. Los techos corresponden a Wirikuta, al cielo diurno y a la montaña del amanecer cerca de Real de Catorce (en el estado de San Luis Potosí), también conocida como Paritekia o Xeu'unari. El oscuro interior de los edificios corresponde al mar y el inframundo, mientras que las fogatas centrales son réplicas del ombligo del mundo, también conocido como Te'akata, "lugar del horno".

Solamente una parte del tiempo-espacio está, por decir, "naturalmente dada”, pues, la mitad solar es artificial y efímera. Periódicamente debe volverse a crear. Como señala Roy Wagner, en culturas 
no occidentales, lo artificial no necesariamente es menos cierto, menos prestigiado o menos importante que lo natural. ¡Al contrario! (cfr. Wagner 1977, 1981).

La mitad de abajo es un mundo antiguo, paleoontológico o prehistórico, pero al mismo tiempo es la modernidad. Habitado por gigantes caníbales, monstruos marinos, chupacabras, vampiros, etcétera. También es el ámbito de las poblaciones no indígenas urbanas, de las tecnologías avanzadas, de los dioses y santos cristianos, de los muertos y de muchas enfermedades, del alcoholismo y de otros peligros.

Los huicholes no se definen como indígenas, sino como los "hermanos menores", "los que llegaron al último", pero de cierta manera se consideran más evolucionados que los mestizos. Como descendientes de los monstruos caníbales, los mestizos tienen un comportamiento asocial. Han perdido el costumbre o nunca lo tuvieron. No conocen lo que los antropólogos llamamos la ley de la reciprocidad. Confiando en su tecnología, desconocen el origen de las cosas; por ejemplo, piensan que la electricidad puede tomarse simplemente del enchufe, sin dar nada a cambio al dios del fuego. Por contraste, los hermanos menores wixaritari deben crear su mundo luminoso a través de la iniciación, practicando yeiyari, "caminando sobre las huellas de los ancestros" o "el costumbre". En este sentido, la idea de "salvar" el mundo es algo ajeno a los huicholes, porque lo que practican es su creación.

Ahora bien, el devaluado mundo de abajo no carece de importancia. Es fuente de fertilidad y riqueza. Incluso el maíz es producto de la alianza con los dioses mestizos. Como me explica el ecologista huichol Pascual Pinedo, el problema es que los dioses de abajo producen "crecimiento no sostenido". Los vientos huracanados y las lluvias que vienen del poniente tienden a ser demasiado fuertes. Kieri y otros dioses mestizos de abajo son poderosos, pero exigentes, caprichosos y déspotas. Sus dones son tan difíciles de manejar que muchos se mueren como consecuencia de haberse relacionado con estas deidades. En general, los intercambios recíprocos son la manera adecuada de relacionarse con los seres del ámbito oscuro de abajo. Esto contrasta con el énfasis en las experiencias sacrificiales de trans- 
formación y multiplicación que predominan en el ritual relacionado con los seres luminosos de arriba.

Estos dos tipos de ritualismo coexisten en muchas situaciones, pero en el fondo son incompatibles. Sobre todo, por eso no tendría sentido una noción de armonía cósmica. Como he señalado en otros trabajos, que no puedo exponer nuevamente con todo detalle, el don recíproco anula el sacrificio transformativo y viceversa (Neurath 2015b). La complejidad relacional implica "condensación ritual" en términos de Houseman y Severi (1998): simultáneamente se viven dos o más relaciones que se contradicen entre sí. Existe una tradición de práctica enfocada en la complejidad de las relaciones que, en el contexto de la sociedad contemporánea, puede entenderse, además de una actividad ritual, como un entrenamiento para vivir en un mundo complicado y contradictorio (Neurath 2018).

\section{MaLOS ENTENDIDOS Y LA ECOLOGÍA WIXARIKA}

Ahora bien, siempre con el debido cuidado para no caer en simplificaciones, vale la pena recapitular cuáles son las diferencias principales con los discursos que normalmente se manejan entre activistas ecologistas. Intentemos, primero, caracterizar el activismo ecologista en términos de una antropología de las ontologías. La tarea es tal vez un poco complicada, porque el naturalismo es influyente, pero coexistente con la ontología que Descola llama "analogismo" (Descola 2005).

Para los ecologistas la naturaleza es, sin duda, algo dado. La existencia objetiva del mundo es una realidad más allá de cualquier cuestionamiento subjetivo o epistemológico. Notablemente, en este punto no existe una diferencia mayor entre las tendencias antagonistas, el ecologismo y el utilitarismo capitalista. La diferencia es que los ecologistas luchan por proteger la naturaleza de la codicia humana, mientras que los utilitaristas capitalistas tratan de sacar el mayor provecho de lo que consideran "recursos naturales". Ambos grupos coinciden en que los recursos naturales son limitados y, por ende, valiosos. ¿Pero debemos rescatarlos o protegerlos o, más bien, explotarlos para el beneficio propio? Según Latour (1999, 2013), el discurso occidental sobre la naturaleza es un callejón sin salida que 
habría que deconstruir para avanzar hacia una mejor relación con las plantas, animales y cosas.

El ambientalismo occidental opera en un tiempo-espacio que se rige, en un principio, según la ontología naturalista, aunque también muestra otros rasgos, incluso animistas, como la atribución de personhood a la tierra (la hipótesis Gaia). El analogismo se manifiesta en el ideal de equilibrio, la preferencia por los procesos circulares y en el deseo de armonía. Sin embargo, como vimos, los wixaritari, que son de una ontología multinaturalista, tienen muy poco interés en nociones de armonía y equilibrio, más bien se enfocan en manejar la complejidad relacional que estructura el cosmos.

Según mi experiencia, la clave para entender las religiones, los rituales y el arte ritual huicholes es la ambigüedad en la relación entre los humanos y los entes del ámbito de alteridad. Es necesario establecer relaciones con animales, ancestros y seres del inframundo, pero esto siempre implica un riesgo. A veces la gente, sinceramente, prefiere no saber de estas cosas, pero hasta cierto punto, es inevitable tener algún tipo de contacto con estos seres. Así que surgen los especialistas rituales o chamanes a quienes se deja la tarea de manejar estas relaciones, como intermediarios y negociadores.

De cierta manera, los mundos de los humanos y aquel de los dioses o espíritus siempre están imbricados, pero la relación raras veces es simétrica. Sea como sea, uno puede cumplir o incumplir compromisos rituales, al final se impondrán los seres del otro mundo. El chamán puede negociar una prolongación del statu quo. Lo que puede lograr no es más que aplazar la muerte.

Creo que éstos son algunos de los aspectos más ilustrativos para observar como los ecologistas que apoyan a los wixaritari en diversas luchas tienen dificultades para entender los principios ontológicos que rigen el mundo wixarika. Los huicholes conviven e interactúan con los existentes de su cosmos complejo: no son parte de una red neurológica biológica gigante, como los nativos de la película Avatar, ni viven lo que sería, en términos de Habermas (1982), un "mundo de la vida" donde aún no existe contradicción con el "sistema".

El mundo wixarika no solamente no es armónico, sino que más bien se puede entender como escindido. El cosmos, como la perso- 
na, es necesariamente "dividual". No debemos subestimar la importancia de la diferencia entre el mundo luminoso de los ancestros y el mundo oscuro de la gente no iniciada. Se puede hablar de una primera creación y una segunda era, que comienza cuando fracasa la primera. Pero ambos mundos son imbricados, muchas veces existen simultáneamente. Si hay una estructura que abarque todo el mundo ritual huichol, sería la que es el resultado de la tensión entre prácticas de intercambio recíproco y de don libre. Un régimen del ser no es simplemente la inversión del otro. La articulación entre ambos es siempre problemática y hace difícil plantear modelos de totalidades sociocósmicas (Neurath 2015b).

En este sentido, podemos afirmar que el naturalismo-analogista de los huicholeros impide que se entienda la complejidad del trabajo ritual wixarika. Sobre todo se enfatizan los intercambios que se entienden como ritos para establecer (o restablecer) relaciones de armonía. Igualmente se piensa que los huicholes usan plegarias similares a las cristianas, para pedir y dar gracias a los dioses.

Un ejemplo que me parece particularmente ilustrativo: "Renovar las velas de la vida" es una frase que los huicholes usan a veces para hablar de sus rituales. Recientemente, un líder político wixarika posteó el siguiente texto en su página de Facebook:

HERMANAS Y HERMANOS, AMIGAS Y AMIGOS, SEGUIDORES Y EL PÚBLICO EN GENERAL [sic]. Nuestro objetivo general es salvaguardar, proteger y defender los lugares sagrados del pueblo Wixárika, principalmente el de Wirikuta. Teniendo como objetivos específicos: Lograr la protección y reconocimiento efectivo de los lugares sagrados reconocidos por el Pueblo Wixárika. Fortalecer el tejido social cultural entre el Pueblo Wixárika y los habitantes de Wirikuta. Seguir con las prácticas tradicionales para seguir renovando las velas de la vida.

Platicando con algunos de los activistas que conocí en ocasión de la gran manifestación en el Cerro Quemado en febrero de 2012, me di cuenta que entendieron el exhorto de las autoridades huicholes de "renovar las velas de la vida" como si se tratara de un exhorto de cumplir con el ritual de las ofrendas de velas, como cuando los cató- 
licos encienden velas frente a figuras de santos en las capillas de sus iglesias. Pero aquí se está hablando de rituales cosmogónicos donde se vuelven a levantar los postes ardientes de ocote hauri, también conocidas como "velas", que separan el cielo y la tierra y que deben ser renovados periódicamente (véase Neurath 2002).

Podrían mencionarse muchos malos entendidos de este tipo. Las visiones se entienden como efectos farmacológicos o, eventualmente, como "teofanías". El peyote, como mencionamos, se entiende como un "enteógeno", que hace a (un) dios presente. No se enfatiza el trabajo ritual, sino las propiedades químicas de la planta y sus efectos $y$, eventualmente, la similitud con el sacramento cristiano de la Eucaristía.

Ahora bien, si los huicholes no cuentan con un concepto de naturaleza, ni con una noción de equilibrio cósmico, ¿̇tiene sentido hablar de un ambientalismo o ecologismo wixarika? El punto de partida del ambientalismo wixarika no es la naturaleza, sino lo que los huicholes llaman kiekari, su organización comunitaria y cósmica. Las prioridades no son como en el ambientalismo teiwari-salvar al planeta y, de paso, a grupos indígenas- sino exactamente al revés. Lugares de culto, "ancestros-topónimos" (Lira 2014), forman parte de la sociedad, no como personas comunes y corrientes, sino como autoridades. De esta manera, para los huicholes, defender el ambiente es, en primer lugar, luchar por mantener una organización política propia, y defender los derechos que los huicholes saben que tienen como comunidades indígenas. En otras palabras, el ambientalismo wixarika es una práctica donde se busca proteger y fortalecer la comunidad sociocósmica (kiekari), a partir de la capacidad chamánica de relacionarse tanto con los ancestros huicholes "de arriba", como con los mestizos "de abajo".

Con todo esto, las luchas huicholas por el cumplimiento de sus derechos como indígenas conllevan un fortalecimiento de la organización comunitaria y, de paso, también una efectiva protección del ambiente. El planeta no es salvado por ellos, sino que se garantizan las condiciones necesarias para seguir creando e inventando el mundo. Siguiendo a Latour (2013), esto sería, de hecho, la verdadera ecología. 
Hablar de modos de existencia es investigar tanto sobre la existencia de cosas (y, de paso, hacer ontología) y sobre todas las relaciones en las que las cosas están involucradas, como sobre los comportamientos y valores que exhiben para poder existir. En este sentido, ontología es ecología (Norton 2013, http://interstitialjournal.files.wordpress.com/2013/10/ norton-latour.pdf). ${ }^{?}$

En su lucha por la defensa de Wirikuta, los huicholes plantearon algo extraordinario en términos ontológicos. Para los juicios donde se alega la necesidad de proteger el paisaje en cuestión, se realizó un "peritaje tradicional", donde los huicholes consultaron los lugares o ancestros-topónimos amenazados en su calidad de personas de alto rango dentro de las comunidades. Las voces de los ancestros, que se escucharon a través de los mara’akate, expresaron su preocupación por la situación. En especial exhortaron a las comunidades de actuar con unidad. La periodista Tracy Barnett describe la escena con estas palabras: "Los cantos paulatinamente se desvanecieron a media mañana, y los mara'akate y los líderes comunitarios tradicionales se reunieron en el centro para discutir, en su lengua wixárika, el significado del mensaje que les habían dado". Casi al medio día se reunieron en el círculo de Tatewarita para compartir su visión con el mundo.

"Ellos (los dioses) están tristes, y piden con lágrimas, llanto y dolor, que no se haga, que no arranquen el corazón, que no saquen la sangre de esta montaña sagrada”, dijo el mara’akame Eusebio de la Cruz, de Santa Catarina, Jalisco, quien transmitió el mensaje de los dioses en su lengua materna, seguido por un traductor. "Quizás lo más importante", dijo: "Pidieron que todos los del pueblo wixárika estén unidos para defender este lugar, y que todos los seres humanos, aun aquellos que invaden y destruyen este sitio sagrado, se unan a nosotros" (http://www.jornada.unam.mx/2012/03/17/camdioses.html, véase Barnett 2012, http:/www.huffingtonpost.com/ tracy-barnett/huicholpilgrimage_b_1264495.html).

9 "To speak of modes of existence is to inquire both into the existence of things (and, thus, to do ontology) and into all the relations into which things enter, as well as the behaviors and values they exhibit, in order to exist. In this sense, then, ontology is ecology”. 
El acto de someter las voces de sus ancestros como prueba en un juicio del mundo mestizo deja ver que los huicholes son muy conscientes de su derecho a la diferencia ontológica y cultural. Pero tal vez lo más notable en este caso fue la negativa de presentarse ellos mismos como víctimas, que va totalmente en contra de la dinámica que normalmente se busca en los juicios. Más bien los huicholes hablaron sobre todo de su propia responsabilidad, en especial de la necesidad de organizarse y de estar unidos en esta lucha. Como dice Barnett (2012):

ese fue un mensaje fuerte para un pueblo que ha estado dividido por casi un siglo con disputas territoriales y de otro tipo que han generado rencor entre las comunidades. Y quizás también fue una indicación, junto con la decisión de permitirnos unirnos a ellos la noche de este ritual, de una nueva apertura por parte del pueblo wixárika con el mundo exterior.

Por orden de los ancestros, los huicholes se aliaron con huicholeros, a pesar de que los no huicholes en un principio carecen de acceso a sus dinámicas cosmogónicas $\mathrm{y}$, permanentemente, viven en un mundo oscuro donde Wirikuta ni siquiera existe (Liffman 2012).

Finalmente, un reto ontológico grande es entender que los huicholes no solamente defienden una organización comunitaria-territorial ya existente, o "en peligro de desaparecer", sino una en construcción, una que se (re)inventa permanentemente. En este proceso, la geografía ritual wixarika se expande y, hoy en día, incluye sitios como la Villa de Guadalupe en la Ciudad de México, la escultura de la Coatlicue en la Sala Mexica del Museo Nacional de Antropología, los sitios arqueológicos de Teotihuacán y Cuicuilco, incluso la Estatua de la Libertad en Nueva York. Estos lugares han sido "sońados" por mara'akate huicholes que los descubrieron, así, como seres ancestrales de los wixaritari. No importa mucho si un sitio haya sido recientemente descubierto como "ancestro-topónimo", o si ha sido visitado ya desde hace muchas generaciones para ser considerado poderoso y muy antiguo. Hay una construcción de la memoria que no opera de una manera linear. Héctor Medina reporta, por ejemplo, que la presa hidroeléctrica de Aguamilpa figura 
ahora en mitos de creación del mundo y existe desde que terminó el diluvio, a pesar de que los narradores vivieron muy de cerca su construcción entre 1989 y 1993 (Medina 2012, 44). Por otra parte, yo documenté como los huicholes de la comunidad Tuapurie tomaron la decisión de no celebrar más el Carnaval (Pachitas) porque era muy caro. A partir de este momento nunca lo han celebrado y la actual versión del calendario festivo es aquel que se practica desde los orígenes del mundo. Menciono estos ejemplos porque el proceso de adopción de nuevos lugares sagrados también funciona así. Una vez que se hayan comenzado a celebrar rituales en un sitio, tienen la misma antigüedad que en cualquier otro punto de la geografía ritual.

En este sentido, es muy probable que incluso Real de Catorce fue un sitio descubierto por chamanes huicholes, en algún momento durante la Colonia, después de que unos huicholes hubieron establecido actividades comerciales con los españoles y mestizos del lugar. Ésta ha sido la hipótesis del arqueólogo Phil Weigand, quien subrayó la importancia del comercio en la historia de los coras y huicholes y planteó que estos grupos hayan llegado a Real de Catorce originalmente para vender sal producida en la costa de Nayarit (Weigand comunicación personal).

\section{REFLEXIONES FINALES}

Para concluir, quiero aclarar que no ha sido mi intención desilusionar a los activistas que apoyan a los huicholes, precisamente, porque los consideran una "cultura milenaria" y "en peligro de extinción", sino quería compartir alguna reflexiones que he hecho durante 25 años, observando como los huicholeros no entienden aspectos fundamentales de la cultura de la gente que apoyan. A mediano plazo será inevitable que los amigos de los huicholes abandonen los discursos esencialistas y paternalistas que hemos esbozado en este ensayo. Los huicholes actúan de manera pragmática y muchas veces no tienen problemas en adaptarse al discurso de sus amigos. Pero el esencialismo es un arma de dos filos: práctico para llegar a las malas conciencias de la burguesía, pero potencialmente contraproducente para la defensa de la autonomía, que es el tema prioritario para los 
huicholes. Por otra parte, para el ecologismo se plantea un problema teórico interesante. ¿Cómo plantear una ecología si la noción de naturaleza no es universal? Al conceptualizar el cosmos en términos de un conjunto complejo de relaciones sociales, los huicholes tienen mucho que enseñar a los que ahora se consideran ambientalistas, pero aún no se dan cuenta que la superación del naturalismo occidental tendría que ser parte de su esfuerzo. Una verdadera ecología debería tener mayor apertura hacia la pluralidad ontológica.

\section{REFERENCIAS}

BARNETT, Tracey L. 2012. "Message from the gods: Unite to defend the Birthplace of the Sun". The Esperanza Project. A Green News Portal for the Americas. http://www.huffingtonpost.com/tracy-lbarnett/huichol-pilgrimage_b_1264495.html

Benítez, Fernando. 1984. Los indios de México II. Los huicholes. Cuarta edición. México: Editorial Era.

Breton, Stéphane, Michèle Coquet, Michael Houseman, JeanMarie Schaeffer, Anne-Christine Taylor, Eduardo Viveiros DE CASTro, eds. 2006. Qu'est-ce qu'un corps? Afrique de l'OuestI Europe occidentale/Nouvelle-Guinée/Amazonie. París: Musée du quai Branly, Flammarion.

Carritiers, Michael, Matei Candea, Karen Sykes, Martin Holbraad y Soumhya Venkatesan. 2010. "Ontology Is Just Another Word for Culture: Motion Tabled at the 2008 Meeting of the Group for Debates in Anthropological Theory". Critique of Anthropology (30).

Descola, Philippe. 2005. Par-delà nature et culture. París: Gallimard. 2013. The Ecology of Others. Chicago: Prickly Paradigm Press.

Descola, Philippe, ed. 2010. La Fabrique des Images. París: Musée du Quai Branly, Somogy editions d'art.

Furst, Peter T. 1968. "Myth in Art: A Huichol Depicts his Reality". Quarterly 7(3):16-25.

1972. "El concepto huichol del alma". En Mitos y arte huicholes, ed. Peter T. Furst y Salomón Nahmad. México: SEP Setentas, 7-113. 
. 1973. "The Roots and Continuities of Shamanism”. Artscanada (184-187): 33-60.

1987. "Huichol Religion". En The Encyclopedia of Religion. Vol. 6, ed. Mircea Eliade, 493-495. Nueva York: Macmillan Publishing Company.

Furst, Peter T. y Barbara Myerhoff. 1972. "El mito como historia: el ciclo del peyote y la datura entre los huicholes". En El peyote y los huicholes, ed. Salomón Nahmad, Otto Klineberg, Peter T. Furst y Bárbara G. Myerhoff. México: SEP Setentas, 53-108.

Galinier, Jacques. 2004. The World Below. Body and Cosmos in Otomi Indian Ritual. Boulder: University Press of Colorado.

Habermas, Jürgen. 1982. Theorie des kommunikativen Handelns, Frankfurt am Main: Suhrkamp.

Henare, Amiria, Martin Holbraad y Sari Wastell. 2007. Thinking Through Things. Theorising Artefacts Ethnographically. Londres: Routledge.

Houseman, Michael y Carlo Severi. 1998. Naven or the Other Self. A Relational Approach to Ritual Action. Leiden: Brill.

Kockelman, Paul. 2016. The Chicken and the Quetzal. Incommensurate Ontologies and Portable Values in Guatemala's Cloud Forest. Durham: Duke University Press.

LAMBERTI, María Julieta. 2014. “¿El Ávatar mexicano? Una sociología no sociocéntrica de los conflictos derivados de la instalación de empresas mineras en territorios indígenas". Intersticios Sociales (8): $1-27$.

Latour, Bruno. 1999. Politiques de la nature. París: Éditions La Découverte.

2013. An Inquiry into Modes of Existence: An Anthropology of the Moderns. Cambridge: Harvard University Press.

Liffman, Paul. 2012. La territorialidad wixarika y el espacio nacional. Reivindicación indigena en el occidente de México. Zamora: El Colegio de Michoacán, Ciesas.

"Huichols and the cosmopolitics of mining in Mexico", 12th EASA Biennial Conference, Nanterre, 10-13 de julio de 2012.

Liffman, Paul, Johannes Neurath, Regina Lira, César Carrillo 
Trueba, Santiago Ruy-Sánchez. 2008. "Caminos impuestos sobre caminos sagrados”. Diario de Campo (98): 95-101.

Lira, Regina. 2014. L'alliance entre la Mère Maïs et le Frère Aîné Cerf: action, chant et image dans un rituel wixárika (huichol) du Mexique. Tesis de Doctorado en Antropología, EHESS.

López Austin, Alfredo. 1980. Cuerpo humano e ideología. Las concepciones de los antiguos nahuas. México: Instituto de Investigaciones Antropológicas-Universidad Nacional Autónoma de México.

Lumholtz, Carl S. 1902. Unknown Mexico. A Record of Five Year's Exploration Among the Tribes of the Western Sierra Madre; in the Tierra Caliente of Tepic and Jalisco; and Among the Tarascos of Michoacan. 2 vols. Nueva York: Charles Scribner's Sons.

Medina, Héctor. 2012. Relatos de los caminos ancestrales. Mitología wixarika del sur de Durango. San Luis Potosí: Universidad Autónoma de San Luis Potosí.

Monaghan, John. 1995. The Covenants with Earth and Rain. Exchange, Sacrifice, and Revelation in Mixtec Sociality. Norman: University of Oklahoma Press.

Myerhoff, Barbara G. 1970. "Deer-Maize-Peyote Symbol Complex among Huichol Indians of Mexico". Anthropological Quarterly (43): 64-78.

. 1974. Peyote Hunt. The Sacred Journey of the Huichol Indians. Ithaca y Londres: Cornell University Press.

Neurath, Johannes. 2002. Las fiestas de la Casa Grande. Procesos rituales, cosmovisión y estructura social en una comunidad huichola. México: Universidad de Guadalajara, Instituto Nacional de Antropología e Historia.

2015a. "La escalera del Padre Sol y Nuestra Madre Joven Águila”. En Cielos e inframundos. Una revisión de las cosmologías mesoamericanas, ed. Ana G. Díaz. México: Instituto de Investigaciones Históricas-Universidad Nacional Autónoma de México. . 2015b. "Shifting Ontologies in Huichol Ritual and Art". Anthropology and Humanism 40(1): 58-70.

. 2018. "Invented Gifts, Given Exchange: The Recursive Anthropology of Huichol Modernity". En The Culture of Inven- 
tion in the Americas. Pedro Pitarch y José A. Kelly. Canon Pyon: Sean Kingston Publishing.

Norton, Michael. 2013. Review of An Inquiry into Modes of Existence: An Anthropology of the Moderns by Bruno Latour. http://interstitialjournal.files.wordpress.com/2013/10/norton-latour.pdf

Povinelli, Elizabeth A. 2013. “¿Escuchan las rocas? La política de la aprehension del trabajo aborigen australiano”. En Cosmopoliticas. Perspectivas antropológicas, ed. Montserrat Cañedo Rodríguez. Madrid: Trotta.

Powell, Melissa S. y C. Jill Grady. 2010. Huichol Art and Culture: Balancing the World: Featuring the Robert M. Zingg Collection of the Museum of Indian Arts and Culture. Albuquerque: University of New Mexico Press.

Rosaldo, Renato. 1991. Cultura y verdad. Nueva propuesta de análisis social. Colección Los Noventa. Traducción de Wendy Gómez Togo. México: Consejo Nacional para la Cultura y las Artes, Ed. Grijalbo.

SAHLIns, Marshall D. 1999. "What is Anthropological Enlightenment? Some Lessons of the Twentieth Century". Annual Review of Anthropology (28): I-XXIII.

Schaefer, Stacy B. y Peter T. Furst, eds. 2006. People of the Peyote. Huichol Indian History, Religion, and Survival. Albuquerque: University of New Mexico Press.

Trouillot, Michel-Rolph. 1991. "Anthropology and the Savage Slot”. En Recapturing Anthropology. Working in the Present, ed. Richard G. Fox, 17-44. Santa Fe: School of American Research. Tsing, Anna Lowenhaupt. 2004. Friction: An Ethnography of Global Connection. Princeton and Oxford: Princeton University Press.

Viveiros de Castro, Eduardo. 1998. "Cosmological Deixis and Amerindian Perspectivism". Journal of the Royal Anthroplogical Institute 4(3): 469-488.

2002. A inconstância da alma selvagem (e outros ensaios de antropologia). Sao Paulo: Cosac \& Naify.

2015. The Relative Native. Essays on Indigenous Conceptual Worlds. Chicago: Hau Books. 
Wagner, Roy. 1977. "Scientific and Indigenous Papuan Conceptualizations of the Innate: A Semiotic Critique of the Ecological Perspective". En Subsistence and Survival, ed. Timothy BaylissSmith y Richard Feachem. Nueva York: Academic Press.

. 1981. The Invention of Culture. Chicago: University of Chicago Press.

Wasson, Gordon, Albert Hoffman y Carl A. P. Ruck. 1980. El camino a Eleusis. Una solución al enigma de los misterios. México: Fondo de Cultura Económica.

Weigand, Phil C. 1992. Ensayos sobre el Gran Nayar. Entre coras, huicholes y tepehuanos. México: Centro de Estudios Mexicanos y Centroamericanos de la Embajada de Francia en México, Instituto Nacional Indigenista, El Colegio de Michoacán.

Znamenski, Andrei. 2007. The Beauty of the Primitive. Shamanism and Western Imagination. Oxford: Oxford University Press. 